Revista de Estudios Histórico-Jurídicos

[Sección historia del derecho indiano]

XXXIX (Valparaíso, Chile, 2017)

[pp. 195 - 212]

\title{
De Altamira y Levene a Tau Anzoátegui (Pasando por García-Gallo). Tres aproXimaciones al DereCho INDIANO*
}

[From Altamira and Levene to Tau Anzoátegui (also reviewing García-Gallo). Three approaches to the Law of the Indies]

\author{
Joaquín GarCía-Huidobro** \\ Universidad de los Andes, Santiago, Chile \\ Diego Pérez Lasserre*** \\ Universidad San Sebastián, Chile
}

\begin{abstract}
RESUMEN
A lo largo del siglo XX cabe constatar tres diversas aproximaciones epistemológicas al derecho indiano. La primera, representada por Rafael Altamira y Ricardo Levene, lo estudian poniendo énfasis en los aspectos históricos y sociológicos. Con Alfonso García-Gallo, en cambio, se abre paso una nueva perspectiva, que somete a crítica dicha visión, y aboga por una aproximación de carácter acentuadamente jurídico-legal al objeto de estudio. Con todo, esta concepción parte de algunos supuestos epistemológicos que resultan discutibles, como se muestra en este artículo apoyándose en la crítica que hace la hermenéutica a esas formas de reduccionismo. Estos inconvenientes han
\end{abstract}

\begin{abstract}
Three different epistemological approaches to the Law of the Indies can be evidenced throughout the $20^{\text {th }}$ century. First, the one proposed by Rafael Altamira and Ricardo Levene, emphasizing historical and sociological aspects. Alfonso GarcíaGallo, on the other hand, explores a new perspective that criticizes said vision and stands for a rather markedly legal approach to the matter under consideration. However, this conception is based on a few arguable epistemological assumptions, as this study shows from the hermeneutics' criticism of these types of reductionism. This situation has been worked out by Víctor Tau Anzoátegui who proposes a
\end{abstract}

ReCibido el 13 de mayo y ACEPTADO el 10 de julio de 2017

* Los autores agradecen el apoyo de Fondecyt (n. 1150561) y del Max-Planck-Institut für europäische Rechtsgeschichte.

** Doctor en Filosofía en la Universidad de Navarra y en Derecho por la Universidad Austral (Argentina). Profesor de Ética en la Universidad de los Andes (Santiago, Chile) y miembro de su Grupo de Investigación en Filosofía Práctica. E-mail: jgh@miuandes.cl

*** Licenciado en Derecho de la Pontificia Universidad Católica de Chile, candidato a Magíster en Pensamiento Contemporáneo: Filosofía y Pensamiento Político por la Universidad Diego Portales y profesor de Derecho en la Universidad San Sebastián. E-mail: dplasserre@ gmail.com 
sido resueltos por una tercera concepción del derecho indiano, representada por Víctor Tau Anzoátegui, que busca integrar las dos perspectivas anteriores.

\section{Palabras clave}

Epistemología del derecho indiano - Rafael Altamira - Ricardo Levene - Alfonso García-Gallo - Víctor Tau Anzoátegui - Historia del derecho. third conception of the Law of the Indies seeking to integrate both perspectives.

\section{KEYWORDS}

Epistemology of the Law of the Indies - Rafael Altamira - Ricardo Levene - Alfonso García-Gallo - Víctor Tau Anzoátegui - Law History.

El derecho indiano es un complejo entramado de normas, actos de autoridad, jurisprudencia y costumbres, entre otras fuentes, que a su vez interactúan con elementos culturales y sociales de carácter local. Esta variedad, sumada a la gran cantidad de normas existentes, la dificultad de dilucidar la vigencia de las mismas y la distinta relevancia que se reconocía a unas u otras fuentes dependiendo de la localidad y el momento histórico, dificulta su estudio de gran manera. Así, el derecho indiano muchas veces aparece como una masa obscura, donde es prácticamente imposible hallar un orden. De ahí que no pueda extrañarnos que, a lo largo de la historia, hayan variado significativamente tanto la manera de aproximarse al estudio de sus fuentes como la preponderancia que se les ha dado a unas u otras manifestaciones jurídicas. Esta variedad se observa en la obra de diversos estudiosos del derecho indiano. En este trabajo hemos elegido a un pequeño grupo de ellos que tienen en común el haberse preocupado de cuestiones que corresponden a los que podríamos llamar una epistemología del derecho indiano desde perspectivas diferentes. Dos de ellos (Altamira y García-Gallo) son españoles, los dos restantes hispanoamericanos (Levene y Tau Anzoátegui).

En una primera instancia, tenemos autores como Ricardo Levene (1885-1959) y Rafael Altamira (1866-1951) que se aproximaron a su estudio desde un punto de vista más bien histórico o sociológico. El primero nos dice que el derecho no es algo estático, sino que tiene una vida "dinámica y funcional, al modo de un organismo que se desarrolla sin intermitencias y que acredita su vitalidad bajo la

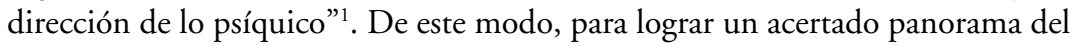
mismo se requiere tener en consideración fenómenos sociales que muchas veces son ajenos a las manifestaciones jurídicas formales. En la misma línea, Altamira explica que "el derecho no es sólo pensado y elaborado intelectualmente por los científicos. Es un género de conocimiento accesible a todos los hombres, en quienes la vida impone esa preocupación (así como la experiencia de los hechos jurídicos) independiente del grado de cultura del sujeto. Existen, en efecto, pensamientos y

${ }^{1}$ LeVEne, Ricardo, Introducción a la historia del derecho indiano (Buenos Aires, Valerio Abeledo, 1924), p. 8. 
sentimientos jurídicos en la masa no profesional del derecho, aun la más iletrada. Ambas cosas adquieren, en circunstancias especiales, una influencia considerable sobre el derecho positivo, ya en la forma de opinión pública permanente más o menos estructurada y provista de órganos de representación y de acción (p.ej. los partidos políticos) ya mediante presiones circunstanciales más o menos violentas (motines, manifestaciones, estados anárquicos, etc.)"2.

Muy distinta es la postura que, con posterioridad a esos autores, asumió Alfonso García-Gallo (1911-1992). Este profesor de la Universidad Complutense de Madrid sometió a crítica dicha visión, y abogó por una aproximación de carácter acentuadamente jurídico-legal al objeto de estudio. Nos dice que "el estudio dogmático, perfectamente compatible con el histórico, del derecho indiano [...] incumbe a los juristas y no a los historiadores" 3 . Agrega asimismo que "El derecho existe con propia entidad y autonomía -cualquiera que sea su posición en la vida de la sociedad y en su cultura-, y consiste en un sistema de ordenación que si bien nace de la sociedad también la encauza y presiona sobre ella, y posee la suficiente complejidad como para haber sido en casi todo tiempo objeto de estudio especializado" ${ }^{4}$. Es decir, en el estudio del derecho indiano desecha cualquier elemento ajeno a lo jurídico (entendido este término en un sentido muy restringido).

La posición representada por García-Gallo fue mayoritaria en dicha área del saber por mucho tiempo. Una consecuencia suya fue el predominio que numerosos autores reconocieron a la ley en el marco de las fuentes del derecho. Con todo, en una época posterior, otros estudiosos, en especial Víctor Tau Anzoátegui (1933-), han reconsiderado la aproximación al fenómeno jurídico indiano que ha de tener el investigador. Al hacerlo, no buscan dar preponderancia a una posición sobre la otra, sino más bien equilibrar estos enfoques antagónicos; es decir, se busca integrar la historia y la sociología dentro de la visión del jurista, para así "descubrir en el pasado o t ro derecho distinto al consagrado por la dogmática en los tiempos modernos"

En lo que sigue, intentaremos hacer una breve síntesis de las ideas centrales presentes en el pensamiento de Ricardo Levene y Rafael Altamira (I); luego analizaremos la postura de Alfonso García-Gallo en lo que se refiere al estudio del derecho indiano (II),y haremos ver algunas dificultades que plantea esta postura desde una perspectiva filosófica (III); a continuación expondremos el intento de mediación realizado por Tau Anzoátegui sobre el asunto (IV), para terminar, por último, con un breve análisis de todo lo expuesto $(\mathrm{V})$.

\footnotetext{
${ }^{2}$ Altamira, Rafael, Manual de investigación de la historia del derecho indiano (México D.F, Editorial Stylo, 1948), p. 51.

${ }^{3}$ García-Gallo, Alfonso, Panorama actual de los estudios de historia del derecho indiano, en Revista de la Universidad de Madrid,1 (1952), p. 61.

${ }^{4}$ García-Gallo, Alfonso, Metodología de la historia del derecho indiano (Santiago, Editorial Jurídica de Chile, 1970), p. 23.

5 TAU Anzótegui, Víctor, Nuevos horizontes en el estudio histórico del derecho indiano (Buenos Aires, Instituto de Investigaciones de Historia del Derecho, 1997), p. 21.
} 


\section{LAS FECUNDAS Y VIVAS FUENTES ADHERIDAS A LA \\ entraña social: Ricardo Levene y Rafael Altamira}

Para Ricardo Levene, el estudio del derecho indiano presenta un carácter complejo al menos por dos razones: primero, porque en esa época nos encontramos ante una legislación múltiple y heterogénea, y segundo porque las manifestaciones jurídicas del mismo no se agotan en la ley. Así, en las Indias existía un derecho vivo que se formaba "al calor de los intereses de la sociedad y al contacto fecundo de sus corrientes encontradas" ${ }^{y}$, que, por lo tanto, "reclama para su estudio la contribución solitaria y armónica de muchos"7. De esta manera, cuando se trata de dilucidar la realidad de una sociedad, el elemento jurídico ciertamente es esencial, pero debe ser complementado por otras ramas del saber para la cabal comprensión de la misma. En efecto: "a través de la vida del derecho -y por su interpretación desde las zonas de la historia y la sociología- se pulsa el ritmo regular y se ausculta el proceso de formación gradual de la coexistencia organizada, conforme a los fines de justicia y bienestar colectivos sin cesar renovados"8.

Dos consecuencias fundamentales se infieren de una posición como esta. En primer lugar, la ley necesariamente deja de ser el centro de atención, con lo que se produce una ampliación del panorama de fuentes que deben ser consideradas por los investigadores. En segundo término, dado que la labor del estudioso se centra en el descubrimiento de un derecho vivo e impregnado de fenómenos socioculturales, la investigación se hace considerablemente más difícil ${ }^{9}$. Esto resulta evidente si tomamos en consideración la cantidad de conocimientos que requiere el investigador para una cabal compresión del mismo; el número de fuentes que ha de revisar, y la viveza que ha de tener para no dejar pasar cuestiones que, a primera vista, pueden parecer de escasa monta pero que resultan esenciales a la hora de armar este rompecabezas histórico. No ha de extrañarnos, por lo tanto, que Levene afirme que el estudioso debe centrar su atención en las fuentes paralelas a la ley, toda vez que "de esas fecundas y vivas fuentes -ocultas en el pasado pero adheridas a la entraña social- mana la savia que vivifica el texto de la ley y la sustenta vigorosa, como al árbol la raíz"10.

Una posición semejante es mantenida por Rafael Altamira. Este autor nos indica que la experiencia vital del día a día en Hispanoamérica es mucho más relevante que lo que aparece de manifiesto en los documentos oficiales. "La legislación constituye un primer paso, necesario, pero de modo alguno satisfactorio para el

${ }^{6}$ LeVEne, Ricardo, Notas para el estudio del derecho indiano (Buenos Aires, Coni, 1918), p. 6.

7 Ibíd.

${ }^{8}$ LeVene, Ricardo, Introducción, cit. (n. 1), p. 3.

9 Tau Anzoátegui, Víctor, Diálogos sobre derecho indiano entre Altamira y Levene en los años cuarenta, en Anuario de Historia del Derecho Español, 67 (1997), p. 367.De hecho, según "Levene, la especulación sociológica sólo era posible cuando la investigación histórica la hubiese precedido o la acompañara. De ahí que sostuviera que el sociólogo debía hacer al propio tiempo labor de historiador", aunque sin confundir ambas disciplinas: TAU ANZOÁTEGUI, Víctor, De la sociología al derecho indiano: contrapuntos entre Ricardo Levene y Ernesto Quesada, en Revista de Historia del Derecho, 34 (2006), p. 367.

${ }^{10}$ Levene, Ricardo, Notas, cit. (n. 6), p. 9. 
estudioso"11; así, el investigador no ha de abocarse exclusivamente a estudiar la ley, pensando que ella constituye un reflejo de la realidad jurídica, sino que ha de internarse en un mundo mucho más complejo, compuesto de múltiples fuentes que interactúan entre sí. En palabras de Altamira: "en cuanto al conocimiento exacto de cómo vivió el derecho un pueblo, depende de otro género de investigación, ciertamente muy difícil y apenas sí intentada alguna vez; pero necesaria si queremos llegar a la plena verdad histórica" ${ }^{2}$.

De lo anterior, y en concordancia con lo dicho sobre Levene, resulta que la persona del investigador adquiere especial relevancia justamente por el especial (y abundante) conocimiento y la singular perspicacia que se requieren a la hora de enfrentarse al material disponible. En efecto, al ampliarse el panorama se hace más difícil la tarea de reconstruir la realidad jurídica indiana. Por esto Altamira afirma que "el buen conocimiento de las fuentes del derecho [...] no depende sólo de la aplicación del método [...]. Todavía más que de éste, depende de la cultura general histórica del investigador en cuanto le permita, o no, percibir cuestiones (es decir aspectos de la realidad que estudia y relaciones entre los hechos) más o menos numerosas y profundas. Si no posee esa cualidad el investigador podrá pasarse años leyendo documentos sin sacar de ellos otra cosa que lo que aparentemente en la superficie expresan, es decir, resultados vulgares y de pobre densidad"13.

En definitiva, para estos autores el fenómeno jurídico indiano está lejos de ser algo fijo o cristalizado en ciertas normas. Hay un inevitable dinamismo que le es característico y le da vida. Un documento nos podrá decir mucho acerca de las pretensiones que los legisladores tuvieron al momento de elaborarlo, pero poco acerca del verdadero derecho ${ }^{14}$.

\section{El ESTUDIO DEL DERECHO INDIANO INCUMBE A LOS JURISTAS Y NO A los historiadores: Alfonso García-Gallo}

Luego de revisar la visión histórica-sociológica de Ricardo Levene y Rafael Altamira, nos corresponde analizar la de Alfonso García Gallo. Este autor, luego de realizar una breve síntesis de la evolución que ha sufrido el estudio del derecho hispano-americano, critica la forma en que sus antecesores se aproximaron al fenómeno jurídico indiano. Nos dice que, en un comienzo, "el estudio histórico del derecho indiano como objeto específico y no sólo en su repercusión política o social, era tarea propia de los juristas y fue iniciada por ellos" 15 , pero que lamentablemente "con la independencia de Hispanoamérica desapareció todo

${ }^{11}$ Tau Anzóftegui, Víctor, Diálogos, cit. (n. 9), p. 379.

12 Altamira, Rafael, Técnica de investigación en la historia del derecho indiano (México D.F., Porrúa, 1939), p. 39.

${ }^{13}$ Altamira, Rafael, Manual, cit. (n. 2), p. 26.

${ }^{14}$ Sobre la colaboración intelectual entre estos autores que mantienen una distancia crítica acerca del positivismo legalista entonces imperante y su influencia en otros campos del derecho,Tau Anzó́tegui, Víctor, De la sociología, cit. (n. 9).

${ }^{15}$ García-Gallo s Alfonso, El desarrollo de la historiografia jurídica indiana, en Revista de Estudios Políticos, 70 (1953), p. 167. 
interés por la historia del derecho indiano"16. Por fortuna, señala, dicho olvido no duró mucho, pues los historiadores fueron a su rescate y retomaron su estudio e investigación. Sin embargo, piensa el jurista español que estos erraron, pues no supieron abordar de manera correcta el derecho indiano. Así, "en la mayoría de los casos estos historiadores se limitaron a reunir materiales que interesaban a la historia jurídica o se ocuparon más o menos incidentalmente de ella sólo en cuanto la misma contribuía a explicar hechos de carácter general" ${ }^{17}$. La principal dificultad, entonces, consiste en que la manera en que los historiadores se aproximaban a las fuentes era muy distinta de aquella que debería ser la propia de un jurista. Para los primeros, "el sistema institucional constituía [...] un simple aspecto de los problemas que le ocupaban, mientras que para los segundos era él [el derecho], precisamente, el objeto inmediato de su atención"18. Así, los historiadores que se dedican al estudio de las fuentes jurídicas indianas se acercan "más que con la preocupación de analizarlas como manifestaciones del derecho, con el de conocer la organización política, administrativa, económica o social de los pueblos y su influencia en la vida de éstos para llegar al conocimiento del pasado" ${ }^{19}$. Esto implica un abandono de la centralidad del fenómeno jurídico, dando paso a que se encuentre en el mismo nivel que otras realidades sociales; es decir, ya no nos encontramos ante una historia del d e r e c h o (es decir, de esa disciplina), sino que ante una h i s t o r i a del derecho. Lo relevante así pasa a ser la historia, que, para lograr una cabal compresión, estudia el fenómeno jurídico como uno más entre otros.

Si bien García-Gallo critica severamente la aproximación histórica imperante en el estudio del derecho indiano, no cabe creer que está realizando un reproche a los historiadores o sociólogos en general. Su ataque se centra más bien en la falta de independencia epistemológica de la historia del derecho. Así: "la historia del derecho no es más importante que la de la economía, la sociología o la política, y no pretende suplantar a éstas; pero no es tampoco una disciplina subordinada a ellas, ni de menor interés. Cada una tiene sus fines, su propio campo y sus métodos. Lo que hay que lograr es que la historia del derecho se mantenga dentro de sus propios límites. Que sea una ciencia jurídica por su contenido y sus métodos"20.

Tampoco cabe entender que nuestro autor esté abogando porque los historiadores dejen de lado este fundamental aspecto en su estudio. De hecho, dice todo lo contrario cuando advierte la necesidad de "que los historiadores se ocupen de las instituciones políticas, administrativas, económicas y sociales, [pero] sólo en la medida necesaria para completar el cuadro de la vida indiana" 21 .

Por fortuna, escribía García-Gallo en 1972, los juristas retomaron el estudio del derecho indiano, aunque este esfuerzo nuevamente resultó ser insuficiente. Esto sucedió principalmente por dos razones: primero, por ignorancia, ya que "se

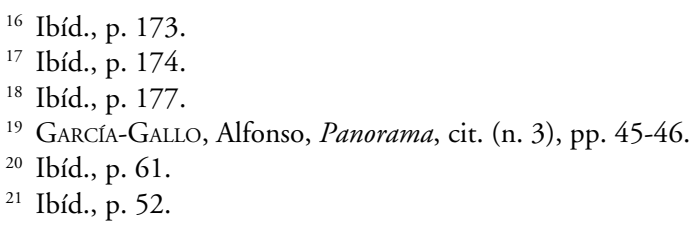


mostraron desconocedores de la labor que paralelamente venían realizando los historiadores generales y no acertaron a explotar los escritos de éstos"; y segundo porque su trabajo se llevó a cabo con una orientación diversa de laque él habría esperado. En efecto, "respondiendo al predominio que entonces alcanzaba la Sociología, como ciencia que aspiraba a conocer en sus grandes líneas los fundamentos y tendencias evolutivas de la vida social, [...] trataron algunos juristas de estudiar el derecho pasado conforme a estas nuevas orientaciones" 22 . Nos encontramos, así, ante dos aproximaciones al estudio del derecho indiano que no cumplen con los criterios jurídicos necesarios para una correcta comprensión del objeto de estudio $y$, por tanto, ignoran lo que realmente constituye su verdadero $s$ e $r$.

De lo dicho cabe constatar una notoria incomodidad intelectual de GarcíaGallo ante los juristas que actúan como historiadores o sociólogos, pues, en su opinión, la gran mayoría de ellos manifiestan "cierta desviación de lo que debiera ser su propio objetivo: como ocurre cuando toman de los historiadores sólo su técnica - p. ej. Altamira-, o se ocupan del derecho como un factor sociológico -p. ej., Levene-, o se limitan a una exposición meramente externa de la historia de las leyes y recopilaciones y de algunas instituciones" ${ }^{23}$. El derecho, nos dice, "es una ordenación de la vida social que posee fuerza vinculante. Es sólo una ordenación, no la vida social misma en toda su complejidad [...] Por eso no se puede justificar, en modo alguno, confundir la ordenación con lo ordenado" ${ }^{24}$. La finalidad principal de este autor es, por tanto, reafirmar la autonomía del derecho frente a otras disciplinas para así depurar su estudio y rescatar lo verdaderamente jurídico. Para él, "la tarea principal de los juristas científicos" debe ser la "construcción dogmática" 25 . Vale la pena detenerse con cierto detalle en la viabilidad epistemológica de su proyecto intelectual.

\section{EL DERECHO INDIANO OBJETIVADO EN SÍ MISMO: LA PRE-COMPRENSIÓN JURÍdica de AlFonso GarcÍA-Gallo}

Una vez expuestas las ideas de Alfonso García-Gallo acerca de qué es el derecho indiano y cómo un investigador debe aproximarse a su estudio, nos encontramos preparados para abordar manera en que, según él, han de proceder los investigadores a la hora de estudiar las fuentes disponibles para extraer de ellas su contenido jurídico y su pretensión de que el investigador debe ser un jurista y centrar su atención exclusivamente en fuentes jurídicas. Una lectura de sus obras permite percatarse de una cuestión de suma complejidad e importantes repercusiones prácticas, a saber, la pretensión de objetivismo que exige a los estudiosos del derecho indiano. En efecto, ciertos pasajes de sus obras parecen indicar que la labor investigativa de los estudiosos del derecho indiano ha de ser prácticamente equivalente a la de un científico en su laboratorio, es decir, debe realizarse con métodos objetivos y resultados exactos, sin sufrir los condicionamientos de la po-

\footnotetext{
22 García-Gallo, Alfonso, El desarrollo, cit. (n. 15), p. 180.

23 García-Gallo, Alfonso, Panorama, cit. (n. 3), p. 52.

${ }^{24}$ García-Gallo, Alfonso, Metodología, cit. (n. 4), p. 17.

25 García-Gallo, Alfonso, Panorama, cit. (n. 3), p. 60.
} 
lítica, la economía y la sociología ${ }^{26}$. Sobre el particular, salta a la vista el siguiente fragmento de su obra Metodología de la historia del derecho indiano, donde señala que: "un texto legal, un comentario del mismo, una sentencia judicial que lo aplica y que nosotros tenemos a la vista, nos permite conocer su propia existencia; y gracias a ello, tratar de conocer y comprender qué y cómo era aquella ley, aquel comentario o aquella sentencia. El objeto de nuestra atención se nos presenta de modo directo, real, tangible, objetivado en sí mismo, sin la deformación que puede darse cuando alguien nos habla de él o trata de explicarnos cómo era. Todas las otras fuentes de conocimiento que en sí mismas no tienen carácter jurídico, suponen siempre una mediatización entre lo que siendo jurídico en ellas se recoge y nuestra propia percepción; entre ellas está interpuesta la personalidad del autor de la fuente: historiador, geógrafo, literato, etc." 27.

Lo que podemos extraer de este pasaje es que, para el autor, el m é t o d o d e e x t r a c c i ó n de lo propiamente jurídico ha de estar exento de toda subjetividad. La percepción y re-transmisión de una fuente del derecho implica una necesaria deformación del material original que ha de ser evitada a toda costa. Así, por ejemplo, el estudio que un historiador experto realiza, basado en diversos documentos públicos y privados, sobre la realidad jurídica imperante en Hispanoamérica carecería de la objetividad necesaria para ser considerada como objeto de estudio de un jurista. El valor histórico de dicho documento puede ser innegable, pero no por ello va a tener valor jurídico. Para ser consecuente con lo antes señalado, el investigador debería ocuparse de depurar las fuentes del derecho indiano de todas las a d i c i o n e s ajenas al derecho causadas por las intromisiones de otras áreas del conocimiento ${ }^{28}$.

Con todo, el planteamiento de García-Gallo adolece de dos dificultades insalvables, que han sido puestas de relieve por la filosofía práctica del último medio siglo. El primero es tan obvio como el hecho de que el jurista no se encuentra ante normas aisladas sino, particularmente en el caso del derecho indiano, se enfrenta, como reconoce el propio García-Gallo, a un mundo abigarrado de leyes, reales cédulas, normas reglamentarias, sentencias y costumbres. Pero su análisis c i e n t í f i c o exigiría un empeño semejante al de llevar a cabo un estudio en una escala 1:1, lo que resulta manifiestamente imposible. Se hace necesario establecer ciertos criterios para determinar, en ese marasmo que se presenta al historiador del derecho, qué debe considerarse como relevante y significativo. Y eso significa que ha de acudir a ciertos criterios de selección que distan de ser neutrales ${ }^{29}$. No

${ }^{26}$ La crítica que realiza Luigi Nuzzo a esta aproximación en Nuzzo, Luigi, Between America and Europe. The Strange Case of the derecho indiano, en Duve, Thomas y PIHLAJAMÄKI, Heikki, en New Horizons in Spanish Colonial Law Contributions to Transnational Early Modern Legal History, (Frankfurt a M., Global Perspectives on Legal History, Volume 3, Max Planck Institute for European Legal History, 2015), pp. 161-191, esp. pp. 164-170.

${ }^{27}$ García-Gallo, Alfonso, Metodología, cit. (n. 4), p. 27.

${ }^{28}$ Cfr. Nuzzo, Luigi, Between, cit. (n. 26), p. 167. Resulta interesante destacar la coherencia de este empeño cientificista con el contexto histórico español, caracterizado por el intento de d e s p o 1 i t i z a r la sociedad.

${ }_{29}$ FinNis, John, Natural Law and Natural Rights (Oxford, Oxford University Press, 2011), cap. I. 
lo serían, por ejemplo, los que acudiesen simplemente a la relevancia h i s t ó r i c a o s o c i o ló gi c a de determinadas normas, pues al hacerlo ya estaría contaminando su objeto con consideraciones que van mucho más de lo meramente jurídico, que era el mal que precisamente quería evitar. Además, García-Gallo no está definiendo adecuadamente qué entiende por d e r e c ho (su afirmación de que se trata de "una ordenación de la vida social que posee fuerza vinculante" es muy amplia y valdría incluso para las órdenes que da un mafioso en un barrio periférico), lo que a su vez plantea problemas de justificación que difícilmente podrían sostener una doctrina que se presente como científica. Considerar, por ejemplo, que por d e r e ch o entendemos las le ye s implicaría caer no solo en un reduccionismo inaceptable, sino incurrir en un grave anacronismo, pues significaría proyectar al mundo pre-ilustrado categorías que sólo tuvieron vigencia a partir del siglo XIX. Esta postura tendría consecuencias políticas importantes, en la medida en que desatiende a la costumbre, la fuente del derecho de carácter más popular y de producción no estatal, mientras que privilegia a la ley, cuya producción es monopolio del Estado. Nuestro autor no aclara estas cuestiones y bien podrían interpretarse en este sentido algunas de sus afirmaciones ${ }^{30}$.

Por otra parte, García-Gallo olvida que la positividad de las normas es sólo potencial, pues para que surja el derecho real se requiere de un plus, a saber, la ipsa res iusta, "el recto actuar y la decisión correcta en la situación concreta" 31 . Arthur Kaufmann establece un claro paralelo entre la ley y el derecho, fundado en la obra de Tomás de Aquino ${ }^{32}$. Así, el derecho se comporta respecto de la ley como el acto frente a la potencia; es la realidad jurídica, frente a la ley, que es mera posibilidad. Si la ley es una norma general para una multiplicidad de casos posibles, el derecho, al contrario, decide una situación real aquí y ahora. El derecho es concreto, mientras que la ley abstracta. Hacer del estudio del derecho una investigación acerca de las leyes significa tanto como mutilarlo. Ante las concepciones racionalistas del derecho, que lo entienden como un conjunto de normas perfectamente determinadas y fijas, Kaufmann reivindica una idea mucho más antigua y también más actual: el derecho como un acto, es decir, como un acontecimiento humano que, aunque requiere de la orientación de una norma, no se identifica con ella ${ }^{33}$.

La pretensión de objetividad de García-Gallo es consecuencia de su idea de la necesidad de independencia de la historia del derecho, pero el plantearla de esta manera genera una serie de inconvenientes. En efecto, al señalar el autor que "la personalidad del estudioso debe ceder ante ello [la necesidad de obtener una

${ }^{30}$ Para Nuzzo, un crítico suyo, la estrategia de García-Gallo consiste precisamente en exaltar el papel de la ley como fuente del derecho en el siglo XVI americano y criticar, al mismo tiempo, la metodología utilizada hasta ese momento para estudiar el derecho indiano. Cfr. Nuzzo, Luigi, Between, cit. (n. 26), p. 167.

${ }^{31}$ Kaufmann, Arthur, Die 'ipsaresiusta’. Gedanken zu einer hermeneutischen Rechtsontologie, en Kaufmann, Arthur, Beiträge zur Juristischen Hermeneutik (Köln, Carl Heymanns Verlag, 1984), p. 60.

${ }^{32}$ Cfr. SumaTeológica II-II, 57, 1 ad 2.

33 Kaufmann, Arthur, Die'ipsa res iusta', cit. (n. 31), p. 59. 
imagen exacta de lo jurídico]; una visión subjetiva, aunque puede ser del máximo interés, corre siempre el riesgo de no captar exactamente la realidad del objeto examinado" 34 , uno no puede sino preguntarse ¿por qué en la investigación jurídica es posible conseguir escapar a cualquier interferencia entre el sujeto que investiga y el objeto investigado?, ¿cómo es que el investigador jurista logra despojarse de su propia personalidad a la hora de investigar? La verdad es que el afirmar que en las ciencias del espíritu existe un conocimiento objetivo al que es posible acceder sin consideración alguna de la subjetividad del ser humano es una cuestión delicada. Desde luego que el pretender la mayor rigurosidad posible e intentar desechar las opiniones arbitrarias de un investigador inexperto o impulsivo es algo deseable y que debe ser buscado, pero eso no significa que debamos (o siquiera podamos) prescindir del elemento humano en el acto del conocimiento. Como bien señala Kant, "sin sensibilidad ningún objeto nos sería dado y, sin entendimiento, ninguno sería pensado" ${ }^{35}$; es decir, no bastan los meros datos sensibles para que haya conocimiento, sino que el entendimiento, y con esto la subjetividad, son necesarios a la hora de aproximarse a cualquier objeto. El que un objeto requiera para su conocimiento el despojarse de toda subjetividad implicaría que dicho objeto se encuentra más allá de nuestras posibilidades de conocimiento y es, por lo tanto, incognoscible (por lo menos empíricamente); en otras palabras, no podemos sino conocer según el modo esencialmente subjetivo del conocer humano. Ahora, si bien el análisis de Kant tiene su punto de partida en el campo metafísico, el considerar que en todo conocimiento hay un elemento subjetivo tiene relevantes consecuencias prácticas que vienen al caso. Como bien señala Herrera, "nuestro modo de ver el mundo determina los resultados de nuestras observaciones. No ve igual el partido de fútbol un hincha que un observador imparcial. Tampoco explicará de igual forma la realidad social chilena un capitalista que un comunista" ${ }^{36}$. En otras palabras, hay algo que inevitablemente nosotros proyectamos en lo que conocemos en el acto de conocimiento ${ }^{37}$.

Sin embargo, y tal como aparece de manifiesto en los ejemplos antes citados, esto acarrea un problema. La pre-comprensión de la realidad que el sujeto tiene y proyecta en lo conocido genera una distorsión que produce que la verdad se torne en algo borroso, cubierta de una neblina que no permite distinguirla con absoluta claridad. No es de extrañar, entonces, que para García-Gallo la manera de

${ }^{34}$ García Gallo, Alfonso, Metodología, cit. (n. 4), p. 15.

35 A-51, B75. Si bien desde el punto de vista filosófico estas ideas toman mayor fuerza en autores posteriores, como los son Heidegger y Gadamer, todos ellos tienen como punto de partida las investigaciones hechas por Kant en su Crítica de la razón pura. Sin embargo, y dada la limitada finalidad del presente trabajo, omitiremos la explicación del tránsito del pensamiento de Kant a estos otros autores. Se ha utilizado la edición de la Crítica de la razón pura traducida por Pedro Ribas: Kant, Immanuel, Crítica de la razón pura (México D.F., Taurus, 2013). Asimismo, se ha utilizado la forma clásica de citar esta obra, es decir, señalando con la letra A la ubicación de la cita en la primera edición de 1781, y con la letra B su ubicación en la edición de 1787.

${ }^{36}$ Herrera, Hugo, Más allá del cientificismo (Santiago, Chile, Universidad Diego Portales, 2011), p. 36.

37 Como bien señala Gadamer, "el que quiere comprender un texto realiza siempre un proyectar”. Gadamer, Hans-Georg, Verdady método (Salamanca, Ediciones Sígueme, 2005), p. 333. 
acceder a la verdadera realidad jurídica indiana haya exigido la eliminación de la subjetividad del investigador, pero con esto hace imposible la investigación misma, pues solo nos aproximamos a los objetos humanos en el seno de una tradición ${ }^{38}$, en ella adquirimos no solo un lenguaje, sino un primer modo de aproximarnos a las cosas mismas, que ciertamente podemos cambiar más adelante, pero es un traslado que siempre se hace de una superficie a otra, no desde la nada.

Ya Aristóteles advertía que en materias prácticas (como la ética, la política o la realidad jurídica) no podemos pretender la exactitud de un geómetra, sino que debemos contentarnos con plantear los problemas y entregar las soluciones de manera esquemática, como en un bosquejo ${ }^{39}$. Esto no significa caer en el relativismo o desesperar de la posibilidad de llegar a la verdad, sino solo tomar conciencia de que, en el terreno práctico, la verdad presenta un carácter muy diferente de aquella que es propia del campo especulativo. Es más, a diferencia de las materias teóricas (como la geometría o la astronomía), donde las disposiciones del carácter no resultan relevantes para la búsqueda de la verdad, en el terreno práctico la historia particular del individuo en cuestión es fundamental para acceder a ella: no están en igualdad de condiciones para resolver un caso un juez experimentado y uno novato, por más que ambos tengan buena voluntad. En la misma línea, Altamira pone de relieve la importancia de las disposiciones del sujeto, incluida su perspicacia, a la hora de aproximarse a la realidad histórico-jurídica, con su multiplicidad de fuentes y de factores que influyen en la práctica del derecho ${ }^{40}$. El pasado se le e de una manera muy distinta a la que es propia de un científico que se halla ante un microscopio.

Retornemos, entonces, al pensamiento de García-Gallo. Si bien la explicación anterior era necesaria para llegar al punto que queremos ahora tratar, no debe pensarse que efectivamente la intención del jurista español pueda haber sido eliminar por completo lo propiamente humano en el conocimiento de las fuentes del derecho. Si bien una primera lectura de varios de sus pasajes parece indicar precisamente eso, estimamos que el entender así su pretensión sería malinterpretar sus palabras. Una relectura de ellas, en cambio, parece aclarar que lo que buscaba era más bien, supuesto que sea posible, deshacerse de elementos correspondientes a otras áreas del conocimiento, como lo son la historia o la sociología, de este inevitable proyectar inherente a la labor investigativa. Es decir, limpiar la vista del investigador para que ésta fuese capaz de penetrar en la esencia de lo que fue efectivamente el derecho indiano. No obstante, es en este punto donde surge una pregunta fundamental. ¿Acaso no está García-Gallo cayendo justamente en la misma subjetivación interpretativa que quería evitar? ¿No es lo jurídico simplemente otra forma de proyectar e incluso ocultar la verdad, en cuanto la reduce a una de sus dimensiones? ¿No es, en determinados casos, el derecho un modo de ocultar la realidad, como ya vieron Burke y Marx en sus célebres críticas a la Declaración Francesa de los Derechos del Hombre, que más que derechos del

\footnotetext{
${ }^{38}$ MacInTYRe, Alasdair, Tres versiones rivales de la ética: enciclopedia, genealogía y tradición (Madrid, Rialp, 1992).

${ }^{39}$ Cfr. por ejemplo, EN II 2, EN II 2, 1103b26-1104a9.

${ }^{40}$ Altamira, Rafael, Manual, cit. (n. 2), p. 26.
} 
hombre eran una mascarada para esconder los derechos de un hombre determinado, el burgués secularizado? Sobre el particular, es relevante revisar lo dicho por Gadamer acerca de la función que realiza el historiador del derecho a la hora de realizar una labor hermenéutica. Él señala que: "En apariencia lo único que le ocupa [al historiador del derecho] es el sentido originario de la ley, a qué se refería y cuál era su intención en el momento en que se promulgó. Pero ¡cómo accede a esto? ¿Le sería posible comprenderlo sin hacer primero consciente el cambio de circunstancias que separa aquel momento de la actualidad? ¿¿No estaría obligado a hacer exactamente lo mismo que el juez, esto es, distinguir el sentido originario del contenido jurídico en cuya pre-comprensión vive como hombre actual? En esto me parece que la situación hermenéutica es la misma para el historiador que para el jurista: frente a un texto todos nos encontramos en una determinada expectativa de sentido inmediata. No hay acceso inmediato al objeto histórico, capaz de proporcionarnos objetivamente su valor posicional. El historiador tiene que realizar la misma reflexión que debe guiar al jurista" ${ }^{11}$.

El historiador del derecho, entonces, no tiene un lugar privilegiado que le permita acceder de manera directa y no distorsionada a su objeto de estudio, que se halla allí en el pasado, incólume, esperando ser conocido de modo impoluto. Él se encuentra en la misma situación que cualquier investigador que indaga en lo histórico, es decir, irremediablemente sujeto a una pre-comprensión e p o c a 1 de lo investigado que inevitablemente guía su mirada y le a g r e g a algo al objeto de estudio.

En suma, tenemos que, si bien con García-Gallo no se eliminó la subjetividad del investigador, sí se produjo un cambio de su perspectiva ante lo jurídico indiano. La historia y la sociología dejó de ser lo proyectado y pasó a tomar su lugar lo estrictamente jurídico: "for it is no exaggeration to state that for more than two decades, both Latin American and Spanish scholarship relied on the epistemologic framework delineated by García-Gallo" ${ }^{42}$. Textos tales como leyes, actos administrativos y documentos oficiales pasaron a colmar la vista de los juristas a tal punto que no quedó espacio para nada más, dejando de lado elementos tan importantes como la labor de los propios juristas y la circulación de los libros. Además, los estudios históricos influidos por el legalismo y la secularización decimonónica, tendieron a dejar de lado el casuismo, que es la aproximación básica al estudio del derecho indiano, y no consideraron el derecho canónico, una fuente fundamental para su comprensión ${ }^{43}$. ¿Podríamos afirmar que estas omisiones permitieron acceder de manera más profunda y directa al derecho indiano?

41 Gadamer, Hans-Georg, Verdad y método, cit. (n. 37), p. 399.

42 Duve, Thomas y PIHLAJAmäKI, Heikki, Introduction: New Horizons of Derecho Indiano, en New Horizons in Spanish Colonial Law Contributions to Transnational Early Modern Legal History (Frankfurt a M., Global Perspectives on Legal History, Volume 3, Max Planck Institute for European Legal History, 2015), p. 1.

${ }^{43}$ TAU ANZOÁTEGUI, Víctor, Zwischen dem spanisch-amerikanischen kolonialen Recht und dem des Nationalstaats in Argentinien (16.-20. Jahrhundert), enZSS.germ.Abt., 133 (2016), p. 443. Este texto contiene una auto-presentación de los intereses científicos de este autor. 


\section{LIMITACIONES DE LA VISIÓN MERAMENTE JURÍDICA}

Para responder esa pregunta, y con la finalidad de verificar si con ello se ilumina un tanto la respuesta, parece ser menester revisar cuál fue el camino que siguió la postura trazada por García-Gallo. Lo haremos siguiendo principalmente a Tau Anzoátegui. Sobre el particular, señala este autor que conviene tener en consideración que la visión jurídica representada por el destacado profesor español imperó por largo tiempo en el estudio del derecho indiano, hasta el punto que "el último balance crítico, acompañado de nuevas propuestas, fue trazado [...] por don Alfonso García-Gallo" "44. Lo anterior trajo como consecuencia que todo aquel que incursionaba en esta área tomaba como punto de partida su obra. Esto sucedía, probablemente, porque ella le otorgaba una seguridad que no podía encontrar en los trabajos anteriores, influidos por la sociología, una disciplina de límites mucho más difusos. Sin embargo, el predominio de la visión jurídico-legal en el derecho indiano, con el consecuente abandono de la perspectiva histórica, no fue visto por todos de manera positiva. En efecto, esa aproximación dejaba en el olvido realidades sociales que es necesario considerar para conseguir tener un panorama completo del fenómeno jurídico. Es más, el mismo concepto de derecho indiano debe ser entendido de manera muy flexible, pues abarca múltiples realidades ${ }^{45}$. Hoy parece claro que el texto de una ley no es suficiente para explicar cómo se llegó a él, por qué era conveniente, a qué necesidad responde, etc. De ahí que, como dice Tau Anzoátegui, exista la necesidad de "renovar aquel ejercicio crítico y de avizorar los nuevos horizontes de la disciplina" ${ }^{4}$.

La perspectiva jurídico-legal enriqueció el horizonte del estudio del derecho indiano, pero es necesario reconocer que también lo estrechó en algunos aspectos. No hay que olvidar que la ley no es el derecho, sino cierta razón del mismo ${ }^{47}$. Como ya se señaló, es el derecho, pero solo en sentido potencial, que debe ser actualizado por las partes en el contrato y el juez en la sentencia, dando lugar al derecho real ${ }^{48}$. La crítica que comenzó a surgir entre los historiadores fue que esta disciplina "se ocupaba sólo de aspectos formales, con prescindencia de los hechos sociales" ${ }^{49}$, es decir, que el jurista se auto-imponía una miopía histórica al limitar su investigación solo a las fuentes tradicionales del derecho (principalmente la ley). Además, tenemos que esta escisión trajo perjudiciales consecuencias, como es la existencia paralela de dos visiones del derecho indiano, una jurídica-legal y otra histórica, que nunca llegaron a entrecruzarse ${ }^{50}$. El resultado de esto fue una ceguera científica, causada por la total ignorancia del material y los descubrimientos

${ }^{44}$ Tau AnzoÁtegui, Víctor, Nuevos horizontes, cit. (n. 5), p. 8.

${ }^{45}$ AвÁsolo, Exequiel, Victor Tau Anzoátegui and the Legal Historiography of the Indies, en Duve, Thomas y PIHLAJAmäKI, Heikki (eds.), New Horizons in Spanish Colonial Law Contributions to Transnational Early Modern Legal History (Frankfurt a. M., Max Planck Institute for European Legal History, 2015), p. 152.

${ }^{46}$ Tau AnzoÁtegui, Víctor, Nuevos horizontes, cit. (n. 5), p. 9.

${ }^{47}$ Cfr. Suma Teológica II-II, 57, 1 ad 2.

${ }^{48}$ Kaufmann, Arthur, Die 'ipsa res iusta', cit. (n. 31).

49 TaU AnZoÁtegui, Víctor, Nuevos horizontes, cit. (n. 5), p. 19.

${ }^{50}$ García-Gallo no desconoce la existencia de fuentes $\mathrm{n}$ o j u r í d i c a s de conocimiento 
de los colegas de la otra disciplina. Como dice Tau: "así fue como la historia del derecho -y naturalmente nuestro derecho indiano- vivió su propia evolución, distinta a la que se producía en el mundo de los historiadores. Este divorcio ha dejado secuelas en unos y otros. Entre los historiadores, el redescubrimiento de materia les juríd icos (testamentos, causas judiciales, literatura jurídica, etc.) y el abordaje de ciertos perfiles de la misma índole se están realizando con visible ignorancia de la información y bibliografía pertinentes. [...] Esto mismo lleva a algunos historiadores a d e s c u b r i r por sí solos, con llamativa ingenuidad, asuntos jurídicos con prescindencia de una actualizada bibliografía histórico-jurídica" ${ }^{51}$.

Cabe, asimismo, tener en consideración que esta visión jurídica pecaba de anacronismo en muchos autores, ya que la primacía de la ley fue el fruto de una filosofía ilustrada que, en buena medida, surgió cuando el derecho indiano se hallaba perfectamente consolidado e incluso iniciaba un período que iba a llevarlo a su decadencia, de modo que difícilmente podía comprender eso orden jurídico en la realidad misma de su existencia. En efecto, la cosmovisión jurídica de las Indias, con su enorme pluralidad de fuentes resulta radicalmente ajena a aquella que es propia del jurista contemporáneo ${ }^{52}$, es decir, del enfoque que postula al derecho como un sistema legal omnicomprensivo establecido por el Estado ${ }^{53}$.

Para lograr tener un panorama omnicomprensivo de la realidad jurídica de la época, se requiere ampliar el espectro de fuentes y criterios utilizados a la hora de estudiar el derecho indiano. "Las altas murallas de derecho o f i c i a l constituyen un cómodo refugio para calificar los actos jurídicos y distinguirlos de los que no lo son, pero al mismo tiempo representan restricciones inadmisibles para el historiador o el sociólogo, propensos a verificar actos o actitudes que ocurren bajo horizontes jurídicos más amplios" ${ }^{44}$. Pretender que la reducción de las fuentes del derecho a la ley va a ir efectivamente acompañada de una mayor certeza jurídica, aparte de ser una ilusión peligrosa desde el punto de vista político, tiene el inconveniente de poner en este organismo el monopolio de la producción jurídica, con todos los inconvenientes que conlleva para la libertad individual. Además, hay que tener presente que las palabras empleadas por el legislador distan de ser unívocas, de modo que solo pueden ser interpretadas a la luz del caso concreto ${ }^{55}$. Y esto, que vale para el jurista, vale también para el historiador, que solo entiende la norma pasada trayéndola al caso presente, lo que únicamente puede hacer

del derecho [cfr. García-Gallo, Alfonso, Metodología, cit. (n. 4), pp. 25-26, 113 ss.] pero ellas no son parte del derecho (cfr. p. 114).

${ }^{51}$ TAU AnZOÁtegui, Víctor, Nuevos horizontes, cit. (n. 5), p. 19.

52 Tau AnzoÁtegui, Víctor, Casuismo y sistema: indagación histórica sobre el espiritu del derecho indiano (Buenos Aires, Instituto de Investigaciones de Historia del Derecho, 1992).

${ }^{3}$ Cfr. Tau Anzó́tegui, Víctor, El jurista en el Nuevo Mundo (Frankfurt a M., Global Perspectives on Legal History 7, Max Planck Institute for European Legal History, 2016), 224.

${ }_{54}$ Tau AnzoÁtegui, Víctor, Nuevos horizontes, cit. (n. 5), p. 25.

${ }_{55}$ KaLINOWSKI, Georges, Filosofia y lógica de la interpretación en derecho. Observaciones sobre la interpretación jurídica, sus fines y sus medios, en Revista Chilena de Derecho 9/2 (1982), pp. 489-96; MassinI, Carlos Ignacio, Derecho y ley: según Georges Kalinowski (Mendoza, Idearium, 1987). 
en la medida en que esté inserto en una determinada tradición ${ }^{56}$. García-Gallo, ciertamente, no cae en el error de restringir las fuentes del derecho a la ley, pero no parece hacerse cargo de que en la medida en que destaque el valor de las otras fuentes, particularmente la costumbre, irá perdiendo la inmediatez y objetividad que exigía a la tarea del historiador del derecho.

En consecuencia, y como bien señala Tau Anzoátegui, es necesaria una renovación de esta área del saber, por lo menos en dos cuestiones fundamentales: en la investigación, donde se debe propender a la existencia de una colaboración entre historiadores y juristas; y en la enseñanza, donde es necesario un nuevo enfoque en la formación de profesionales ${ }^{57}$. El derecho indiano no debe ser seccionado y repartido por partes entre juristas, historiadores y sociólogos, ya que "no se trata de disciplinas distintas, sino de dos formas de mirar el objeto estudiado, de [...] intereses legítimos a los que debe atender, desde su taller, el ius-historiador" 58 para lograr una visión plena de la realidad. Además, la adopción de una visión más flexible ayudará al historiador del derecho a tener mayor libertad, permitiéndole "apartarse de un sofocante e imperativo estatismo y legalismo que atrofia la visión del pasado" 59 .

En definitiva, se trata de tomar en consideración que la forma de abarcar la investigación del derecho hispanoamericano ha de ser necesariamente flexible para una correcta comprensión del mismo ${ }^{60}$, pues de esta manera permite y exige al ius-historiador "salir del estrecho ámbito en donde la dogmática ha encerrado la noción de derecho, con desconocimiento de toda esfera de normatividad que no fuese establecida por la ley positiva de Estado. Una concepción restrictiva es inaplicable a nuestro derecho indiano" ${ }^{61}$.

Un ejemplo claro se observa en el modo en que la costumbre misma actúa en el marco de las fuentes del derecho, que distan mucho de operar como compartimentos estancos. Así, señala Tau: "hay que buscar la costumbre en las leyes, en los decretos del rey, en las actas capitulares, en los títulos de nombramiento, en las escrituras notariales, y en toda huella del pasado para percibir y evaluar su presencia, para otear ese trasfondo consuetudinario que, a mi juicio, anima todo el derecho indiano" ${ }^{2}$. El modo mismo en que operaba el derecho indiano ha sido sometido a un profundo cuestionamiento, pues los historiadores tendieron a aplicar al pasado modelos contemporáneos, donde el derecho era concebido como un orden normativo creado desde arriba en virtud de un poder legislativo de carácter exclusivo, cuya máxima expresión, según ellos, habría sido la Recopilación de las Leyes de Indias de 1680, que habría dejado de lado el carácter particular,

56 Gadamer, Hans-Georg, Verdad y método, cit. (n. 37), p. 401.

57 Cfr. Tau Anzoátegui, Víctor, Nuevos horizontes, cit. (n. 5), p. 21.

58 Ibíd.

59 Ibíd.

${ }^{60}$ Cfr. Nuzzo, Luigi, Between, cit. (n. 26), p.182.

${ }^{61}$ Tau AnzoÁtegui, Víctor, Nuevos horizontes, cit. (n. 5), p. 22.

${ }^{62}$ Tau AnzoÁtegui, Víctor, El poder de la costumbre: estudios sobre del derecho consuetudinario en América hispana hasta la emancipación (Buenos Aires, Instituto de Investigaciones de Historia del Derecho, 2001), p. 14. 
cambiante y casuístico de los derechos locales, o al menos los habría considerado como meramente suplementarios y poco relevantes. Por el contrario, en las últimas décadas, esta visión ha sido profundamente debilitada, mientras que ha ganado fuerza una imagen de multiplicidad, donde las ciudades tuvieron un singular protagonismo. De este modo, se abrió camino a un campo de estudios teóricos "en el que el derecho local no era meramente suplementario, ni tampoco limitado a un área aislada exclusiva del derecho indiano, sino que incluso ha adquirido un nivel de relevancia inesperado, hasta el punto que ofrece una nueva forma de aproximación a todo el sistema jurídico de Hispanoamérica" ${ }^{33}$.

\section{No EXCLUyentes, SINO ACUMUlativas}

A partir de lo recién expuesto, podemos concluir que el estudio del derecho indiano realizado únicamente desde una perspectiva jurídico-legal es insuficiente para trazar un panorama de este fenómeno. Sin embargo, no debe creerse que el trabajo legalista realizado en este ámbito haya sido inútil. La visión de autores como García-Gallo enriqueció de gran manera la perspectiva desde la que se estudiaba el derecho hispanoamericano. Además, "si bien García-Gallo adopta una postura crítica ante ciertos criterios metodológicos de Altamira y Levene, se empeña en llevar adelante una labor directiva de continuidad y no de ruptura" ${ }^{64}$. Así, es relevante insistir en que el tránsito hacia una visión jurídica (en el sentido estricto de la palabra) constituyó una etapa necesaria, pues a la historia y a la sociología les era imposible el abarcar este complejo e intrincado fenómeno que conocemos como derecho indiano sin la ayuda de lo estrictamente jurídico. Así, no es de extrañar que autores como Tau Anzoátegui señalen que "hoy no es posible ocuparse de los estudios de derecho indiano sin tener en cuenta esa labor directiva que, en el orden metodológico y de orientación, desempeñó el maestro español" ${ }^{65}$. Efectivamente se requería introducir conceptos y enfoques jurídicos, ajenos a historiadores y sociólogos, para lograr una independencia de esta rama del saber tanto en su metodología como en su ámbito de estudio. Pero, dado que este objetivo ya está conseguido, ahora es necesario ampliar la perspectiva para que se reencuentren la historia, la sociología y la ciencia jurídica.

No debe, por lo tanto, creerse que existe una superioridad en una u otra visión, capaz de tornar obsoletas a las demás, sino que cada una de estas ha de tomarse como un momento necesario en el desarrollo de la historia de la investigación del derecho indiano, de modo que confluyan en una síntesis donde una precomprensión enriquecida tanto por la historia, como por la sociología y el derecho permita explicar el fenómeno jurídico indiano en sus diversos aspectos. Es decir, se ha de partir "de la solidez alcanzada a través de dos etapas anteriores: la que

63 Tau Anzóftegui, Víctor, Provincial and Local Law of the Indies, en Duve, Thomas y PIhlajAmäKI, Heikki (eds.), New horizons in Spanish colonial law contributions to transnational early modern legal history (Frankfurt a. M., Max Planck Institute for European Legal History, 2015), p. 236.

${ }^{64}$ Tau Anzońtegui, Víctor, Diálogos, cit. (n. 9), p. 373.

65 Tau AnzoÁtegui, Víctor, Nuevos horizontes, cit. (n. 5), p.9. 
corresponde a la impronta sociológica e histórica de Rafael Altamira y Ricardo Levene; y la que produjo el giro de inspiración propuesto por García-Gallo. No son etapas excluyentes, sino acumulativas" ${ }^{\prime 6}$. La dinámica misma del estudio de la historia del derecho apunta a la síntesis.

\section{BiBLIOGRAFÍA}

ABÁsolo, Exequiel, Víctor Tau Anzoátegui and the Legal Historiography of the Indies, en

Duve, Thomas y PihlajamäKi, Heikki (eds.), New Horizons in Spanish Colonial Law Contributions to Transnational Early Modern Legal History (Frankfurt a. M., Max Planck Institute for European Legal History, 2015).

Altamira, Rafael, Manual de investigación de la historia del derecho indiano (México D.F, Editorial Stylo, 1948).

Altamira, Rafael, Técnica de investigación en la historia del derecho indiano (México D.F., Porrúa, 1939).

Duve, Thomas y PIHLAJAMÄKI, Heikki, Introduction: New Horizons of Derecho Indiano, en New Horizons in Spanish Colonial Law Contributions to Transnational Early Modern Legal History (Frankfurt a. M., Global Perspectives on Legal History, Volume 3, Max Planck Institute for European Legal History, 2015).

FInNIS, John, Natural Law and Natural Rights (Oxford, Oxford University Press, 2011). Gadamer, Hans-Georg, Verdad y método (Salamanca, trad. por Ana Agud Aparicio y Rafael de Agapito, Ediciones Sígueme, 2005).

García-Gallo, Alfonso, Panorama actual de los estudios de historia del derecho indiano, en Revista de la Universidad de Madrid,1 (1953), pp. 37-62.

-- El desarrollo de la historiografía jurídica indiana, en Revista de Estudios Politicos, 70 (1953), pp. 163-186.

-- Metodología de la historia del derecho indiano (Santiago, Editorial Jurídica de Chile, 1970).

Herrera, Hugo, Más allá del cientificismo (Santiago, Chile, Universidad Diego Portales, 2011).

KaLINOWSKI, Georges, Filosofía y lógica de la interpretación en derecho. Observaciones sobre la interpretación jurídica, sus fines y sus medios, en Revista Chilena de Derecho 9/2 (1982), pp. 489-496.

Kant, Immanuel, Crítica de la razón pura (México D.F.,traducción de Pedro Ribas, Taurus, 2013).

Kaufmann, Arthur, Die 'ipsa res iusta'. Gedanken zu einer hermeneutischen Rechtsontologie, en ÉLMIsmo, Beiträge zur Juristischen Hermeneutik (Köln, Carl Heymanns Verlag, 1984).

LEVENE, Ricardo, Introducción a la historia del derecho indiano (Buenos Aires, Valerio Abeledo, 1924).

-- Notas para el estudio del derecho indiano (Buenos Aires, Coni, 1918).

MACINTYRE, Alasdair, Tres versiones rivales de la ética: enciclopedia, genealogía y tradición (Madrid, Rialp, 1992).

Nuzzo, Luigi, Between America and Europe. The Strange Case of the derecho indiano, en Duve, Thomas y PinlajamäKI, Heikki, New Horizons in Spanish Colonial Law 
Contributions to Transnational Early Modern Legal History (Frankfurt a. M., Global Perspectives on Legal History, Volume 3, Max Planck Institute for European Legal History, 2015), pp. 161-191.

Tau AnzoÁtegui, Víctor, Casuismo y sistema: indagación histórica sobre el espíritu del derecho indiano (Buenos Aires, Instituto de Investigaciones de Historia del Derecho, 1992).

-- Diálogos sobre derecho indiano entre Altamira y Levene en los años cuarenta, en Anuario de Historia del Derecho Español, 67 (1997), pp. 360-369.

-- El jurista en el Nuevo Mundo (Frankfurt a M., Global Perspectives on Legal History 7, Max Planck Institute for European Legal History, 2016).

-- Nuevos horizontes en el estudio histórico del derecho indiano (Buenos Aires, Instituto de Investigaciones de Historia del Derecho, 1997).

-- De la sociología al derecho indiano: contrapuntos entre Ricardo Levene y Ernesto Quesada, en Revista de Historia del Derecho, 34 (2006), pp. 357-417.

-- El poder de la costumbre: estudios sobre el derecho consuetudinario en América hispana hasta la emancipación (Buenos Aires, Instituto de Investigaciones de Historia del Derecho, 2001).

-- Provincial and Local Law of the Indies, en Duve, Thomas y PinlajamäKI, Heikki (eds.), New horizons in Spanish colonial law contributions to transnational early modern legal history (Frankfurt a. M., Max Planck Institute for European Legal History, 2015.

-- Zwischen dem spanisch-amerikanischen kolonialen Recht und dem des Nationalstaats in Argentinien (16.-20. Jahrhundert), en ZSS.germ.Abt., 133 (2016), pp. 442-473. 